\title{
Race and Inflammatory Bowel Disease in an Urban Healthcare System
}

\author{
Justin L. Sewell • John M. Inadomi • \\ Hal F. Yee Jr.
}

Received: 25 May 2010/Accepted: 19 September 2010/Published online: 9 October 2010

(C) The Author(s) 2010. This article is published with open access at Springerlink.com

\begin{abstract}
Background Inflammatory bowel disease (IBD) is increasingly common among non-Caucasian populations, but interracial differences in disease characteristics and management are not well-characterized.

Aims We tested the hypothesis that disease characteristics and management vary by race among IBD patients in an ethnically diverse healthcare system.

Methods A retrospective study of the safety net healthcare system of San Francisco, CA, from 1996 to 2009 was undertaken. Patient records with International Classification of Diseases, 9th Revision (ICD9) codes 555.xx, 556.xx, and 558.xx were reviewed. Adult patients with confirmed IBD diagnoses were included. Interracial variations in disease characteristics and management were assessed broadly; focused between-race comparisons identified specific differences.

Results The 228 subjects included 77 (33.4\%) with Crohn's disease (CD), 150 (65.8\%) with ulcerative colitis, and 1 $(0.4 \%)$ with IBD, type unclassified. The race distribution included 105 (46.1\%) white, 34 (14.9\%) black, 35 (15.4\%) Hispanic, and 51 (22.4\%) Asian subjects. Asians and
\end{abstract}

J. L. Sewell $(\bowtie) \cdot$ H. F. Yee Jr.

Center for Innovation in Access and Quality, Division of

Gastroenterology and Hepatology, San Francisco General

Hospital, Department of Medicine, University of California

San Francisco, 1001 Potrero Avenue, SFGH NH-3D7, GI Unit,

San Francisco, CA, 94110USA

e-mail: justin.sewell@ucsf.edu

J. M. Inadomi

Division of Gastroenterology and Hepatology, Department

of Medicine, University of Washington, Seattle, WA, USA
Hispanics were diagnosed at older ages (41.0 and 37.1 years, respectively) and had shorter disease durations (5.4 and 5.2 years, respectively) than whites (30.5 years at diagnosis and 8.6 years duration, $P<0.05)$ and blacks $(31.7$ years at diagnosis and 12.1 years duration, $P<0.05)$. CD was more common among blacks (50\% of subjects) than Asians (25.5\% of subjects, $P=0.015$ ). The Montreal classification of IBD was similar among races. Hispanics were less likely than others to be treated with 5-aminosalicylates (5-ASA), immunomodulators, and steroids. Medical and surgical management was otherwise similar among races.

Conclusions Modest race-based differences in IBD characteristics exist in this racially diverse healthcare system, but the management of IBD is similar among race groups.

Keywords Inflammatory bowel diseases . Colitis, ulcerative · Crohn's disease · Race · Ethnic groups · Health status disparities

$\begin{array}{ll}\text { Abbreviations } \\ \text { 5-ASA } & \text { 5-aminosalicylates } \\ \text { CD } & \text { Crohn's disease } \\ \text { CI } & 95 \% \text { confidence interval } \\ \text { IBD } & \text { Inflammatory bowel disease } \\ \text { IBDU } & \text { Inflammatory bowel disease, type unclassified } \\ \text { ICD9 } & \text { International Classification of Diseases, 9th } \\ & \text { Revision } \\ \text { OR } & \text { Odds ratio } \\ \text { SFGH } & \text { San Francisco General Hospital and Trauma } \\ & \text { Center } \\ \text { TNF } & \text { Tumor necrosis factor } \\ \text { UC } & \text { Ulcerative colitis } \\ \text { UCSF } & \text { University of California San Francisco }\end{array}$




\section{Introduction}

Crohn's disease (CD) and ulcerative colitis (UC) were previously considered to be diseases of Caucasian patients, but studies have documented the increasing burden of inflammatory bowel disease (IBD) among non-white populations outside the United States [1-8]. Increasing hospitalization rates among minorities with IBD in the United States may suggest similar trends, but nationwide epidemiologic data (such as incidence and prevalence) are not available [9].

Certain disease characteristics, such as penetrating disease (among patients with CD) [10] and extensive colitis (among patients with UC) [11], are associated with poorer disease outcomes, but studies comparing these important disease characteristics among racially diverse populations are extremely limited. Interracial differences in medical and surgical therapy are also poorly characterized; most of the few existing studies suffer from referral and/or selection bias, and potential healthcare disparities may, therefore, go undetected. To date, only one study evaluated IBD in more than two race groups among patients from the same geographic region [12]. One other study compared IBD among three ethnic groups, but minority subjects were recruited from different centers compared to the white subjects [13].

The safety net healthcare system of San Francisco, CA, serves approximately one-fifth of the city's population and is racially diverse $[14,15]$, providing an ideal setting in which to address the above knowledge gaps. In an effort to better understand associations between race and IBD, we identified IBD patients seen in the gastroenterology clinic serving this entire healthcare system from 1996 through 2009. We compared patients from four race groups to test the hypothesis that disease characteristics and management would differ among race groups. Based on prior studies documenting healthcare disparities among minority patients with other chronic diseases [16, 17], we hypothesized that minority patients would have more severe disease manifestations and be less likely to receive medical and surgical therapy compared with white patients.

\section{Methods}

\section{Study Setting}

The safety net healthcare system of San Francisco, CA, includes residents of the City and County of San Francisco who receive healthcare through an alliance between the San Francisco Department of Public Health's CommunityOriented Primary Care, San Francisco General Hospital and Trauma Center (SFGH), the University of California
San Francisco (UCSF), and the San Francisco Community Clinic Consortium of independent primary care health centers. The healthcare system serves more than 150,000 residents, including nearly $20 \%$ of San Francisco's population $[14,15,18]$. Socioeconomically, the population served by the safety net healthcare system includes the poor and indigent (many of whom receive Medicaid coverage), the Medicare-insured elderly, and working individuals and families with incomes of up to $500 \%$ of the federal poverty threshold enrolled in San Francisco's universal access to healthcare program (Healthy San Francisco) [14]. The Healthy San Francisco program ensures equal access to primary and specialty healthcare services by providing affordable or free medical coverage to residents who are unable to afford commercial medical insurance but who do not qualify for Medicare (approximately $23 \%$ of patients in the healthcare system) or Medicaid (approximately $45 \%$ of patients in the healthcare system) [15]. Specialty services are provided by UCSF faculty and trainees located centrally at SFGH, including the gastroenterology clinic, which provides gastroenterology and hepatology services for the entire healthcare system [19]. Patients in the healthcare system are ethnically diverse, including 20\% African Americans, 25\% whites, $30 \%$ Hispanics, and 20\% Asians [15]. A fully integrated electronic medical record is used to document and coordinate patient care. Patient referrals to specialty clinics are managed through a novel electronic referral system [20].

\section{Study Design}

We performed a retrospective review of adult patients with IBD seen in the gastroenterology clinic from November 1996 through September 2009. Records for all patients seen in the gastroenterology clinic were electronically queried for International Classification of Diseases, 9th Revision (ICD9) codes 555.xx (CD), 556.xx (UC), and 558.xx (other and unspecified noninfectious gastroenteritis and colitis), which were coded by providers at the time of gastroenterology clinic appointments. All subcodes for each primary code were included. Identified charts were reviewed in detail by an investigator (JLS), including clinic notes, hospitalization records, endoscopic evaluations, surgical reports, laboratory testing, microbiological testing, radiologic studies, and pathology results. IBD diagnoses were confirmed using criteria discussed below. Data for patients with IBD were abstracted and assimilated into a statistical database.

\section{Diagnosis of IBD}

IBD diagnoses were confirmed using standard clinical criteria. Subjects lacking endoscopic, pathologic, and/or 
Table 1 Montreal classification scheme

\begin{tabular}{|c|c|}
\hline \multicolumn{2}{|c|}{ Crohn's disease } \\
\hline \multicolumn{2}{|l|}{ Age } \\
\hline A1 & Diagnosis age 16 years or younger \\
\hline $\mathrm{A} 2$ & Diagnosis between age 17 and 40 years \\
\hline A3 & Diagnosis after age 40 years \\
\hline \multicolumn{2}{|l|}{ Location } \\
\hline L1 & Disease isolated to the ileum \\
\hline L2 & Disease isolated to the colon \\
\hline L3 & Disease of both the ileum and the colon \\
\hline L4 & $\begin{array}{l}\text { Disease isolated to the upper gastrointestinal tract } \\
\text { (jejunum or proximal); can be added as a modifier } \\
\text { for patients with coexisting ileal and/or colonic } \\
\text { disease }\end{array}$ \\
\hline \multicolumn{2}{|l|}{ Behavior } \\
\hline B1 & Inflammatory; not stricturing or penetrating \\
\hline B2 & Stricturing, not penetrating \\
\hline B3 & $\begin{array}{l}\text { Penetrating disease, with or without stricturing, } \\
\text { excludes perianal penetrating disease }\end{array}$ \\
\hline $\begin{array}{l}\text { Perianal } \\
\text { modifier }\end{array}$ & Added as a modifier for patients with perianal disease \\
\hline \multicolumn{2}{|c|}{ Ulcerative colitis } \\
\hline \multicolumn{2}{|l|}{ Extent } \\
\hline E1 & Disease limited to the rectum \\
\hline E2 & $\begin{array}{l}\text { Disease proximal to the rectum but distal to the } \\
\text { splenic flexure }\end{array}$ \\
\hline E3 & Disease proximal to the splenic flexure \\
\hline
\end{tabular}

Based on Satsangi et al. [21]

radiologic testing to confirm IBD diagnoses locally at SFGH were included in the study only when historical data were strongly consistent with IBD. We required that such patients: (1) presented to the clinic reporting an established history of IBD, (2) were able to provide details regarding their disease, and (3) reported regular use of IBD medications. Patients with questionable IBD diagnosis were excluded. Based on the consensus statement of the Montreal Working Party, we designate IBD without a clear phenotype of CD or UC as inflammatory bowel disease, type unclassified (IBDU) [21].

\section{Disease Extent, Location, and Behavior}

We used the Montreal classification to categorize disease among patients with CD and UC (Table 1) [21]. Subjects lacking adequate objective data to determine the Montreal classification were excluded from relevant data analysis.

\section{Medication Use}

Details of the subject medication use were obtained through the careful review of clinic records. Data were obtained regarding current and lifetime medication use. To reduce the number of statistical comparisons in our analysis, we chose to report lifetime medication use, because lifetime use reflects longer term utilization patterns compared with current use, which provides only a snapshot in time.

\section{Surgical History}

Reports for operative procedures performed at SFGH were abstracted. Information regarding operative procedures performed at other facilities was obtained from clinic notes.

\section{Designation of Race}

As per the accepted standard [22], race was self-reported at the time of registration at SFGH. Although the designation of Hispanic background is considered as an ethnic identification rather than a race designation, our medical record includes it as a race, and Hispanic patients do not identify additional race designations (i.e., white race and Hispanic ethnicity). We, therefore, included Hispanic identification as a race category in our analyses.

\section{Smoking Status}

Patients were considered to be active smokers when current cigarette use was confirmed at the most recent documentation of smoking history. Patients were considered to be prior smokers if they reported previous cigarette use, but denied current smoking at the most recent documentation of smoking history. Patients were considered to be nonsmokers if they denied any history of cigarette use.

\section{Statistical Analysis}

Race was the independent variable in our study, and we sought to compare multiple dependent variables across race groups. To reduce the number of statistical comparisons and risk of type I error, we performed a single initial statistical test for each dependent variable to broadly evaluate for any significant variation amongst the four race groups. For continuous variables, we used analysis of variance (ANOVA). For categorical variables, contingency tables were constructed including all four race groups; Pearson's $\chi^{2}$ or Fisher's exact test evaluated for statistically significant interracial differences. When these initial tests produced a $P$-value suggestive of interracial differences, individual two-tailed $t$-tests (for continuous variables) or $\chi^{2}$ or Fisher's exact test (for categorical variables) were used to identify specific interracial differences. The standard for statistical significance was $P \leq 0.05$ for all analyses. 
Table 2 Demographics and disease characteristics by race

\begin{tabular}{|c|c|c|c|c|c|c|}
\hline & $\begin{array}{l}\text { Total population } \\
(n=228)^{\mathrm{a}}\end{array}$ & $\begin{array}{l}\text { White } \\
(n=105)\end{array}$ & $\begin{array}{l}\text { Black } \\
(n=34)\end{array}$ & $\begin{array}{l}\text { Hispanic } \\
(n=35)\end{array}$ & $\begin{array}{l}\text { Asian } \\
(n=51)\end{array}$ & $P$-value \\
\hline Percentage of study population & - & 46.1 & 14.9 & 15.4 & 22.4 & - \\
\hline $\begin{array}{l}\text { Proportion of each race in the overall } \\
\text { healthcare system, } 2007^{\mathrm{b}}\end{array}$ & - & 25 & 20 & 30 & 20 & - \\
\hline $\begin{array}{l}\text { Proportion of each race in the overall } \\
\text { San Francisco population, } 2008^{c}\end{array}$ & - & 45.6 & 6.8 & 14.1 & 31.3 & - \\
\hline Female, no. $(\%)^{\mathrm{d}}$ & $94(41.2)$ & $42(40.0)$ & $12(35.3)$ & $16(45.7)$ & $23(45.1)$ & 0.76 \\
\hline Current smoker, no. $(\%)^{\mathrm{d}}$ & $48(21.1)$ & $25(23.8)$ & $18(52.9)$ & $2(5.7)$ & $3(4.8)$ & $<0.001$ \\
\hline Mean age at diagnosis, years $(\mathrm{SD})^{\mathrm{e}}$ & $34.0(14.1)$ & $30.5(11.8)$ & $31.7(14.3)$ & $37.1(16.0)$ & $41.0(14.6)$ & $<0.001$ \\
\hline Disease duration, years $(\mathrm{SD})^{\mathrm{e}}$ & $7.9(9.0)$ & $8.6(9.4)$ & $12.1(13.0)$ & $5.2(5.5)$ & $5.4(5.4)$ & 0.003 \\
\hline Family history of IBD, no. $(\%)^{\mathrm{d}}$ & $37(16.2)$ & $27(25.7)$ & $3(8.8)$ & $4(11.4)$ & $3(5.9)$ & 0.01 \\
\hline Diagnosis, no. $(\%)^{\mathrm{d}, \mathrm{f}}$ & & & & & & 0.11 \\
\hline Crohn's disease & $77(33.4)$ & $37(35.2)$ & $17(50.0)$ & $10(28.6)$ & $13(25.5)$ & \\
\hline Ulcerative colitis & $150(65.8)$ & $68(64.8)$ & $16(47.1)$ & $25(71.4)$ & $38(74.5)$ & \\
\hline Inflammatory bowel disease, type unclassified & $1(0.4)$ & $0(0.0)$ & $1(2.9)$ & $0(0.0)$ & $0(0.0)$ & \\
\hline
\end{tabular}

"Includes three patients with "other" race

b Data from [15]

c Data from [18]

d $P$-value calculated using contingency tables and Pearson's $\chi^{2}$ or Fisher's exact test, as appropriate

e $P$-value calculated using analysis of variance (ANOVA)

${ }^{\mathrm{f}}$ Comparing patients with Crohn's disease (CD) and ulcerative colitis (UC); excludes patients with inflammatory bowel disease type unclassified (IBDU)

All analyses were performed using Stata, versions 10 and 11 (StataCorp, College Station, TX).

\section{Ethical Considerations}

This study was approved by the UCSF Committee on Human Research and the General Clinical Research Center at SFGH.

\section{Results}

\section{Demographics}

The study group included 228 ethnically diverse subjects, including 105 (46.1\%) whites, 34 (14.9\%) blacks, 35 (15.4\%) Hispanics, and 51 (22.4\%) Asians. Three patients reported other races. Compared with the overall healthcare system, there were proportionately more white patients (46.1 vs. $25 \%$ ) and fewer Hispanic patients (15.4 vs. $30 \%$ ) in our study. The proportions of blacks and Asians in our study were similar to the overall healthcare system [15]. The proportions of subjects from each race group were similar to the overall San Francisco population [18] (see Table 2).

\section{Disease Characteristics}

Objective data were available to confirm diagnoses in 187 ( $83 \%)$ of the subjects. The remaining 41 subjects (17\%) did not undergo further testing to confirm diagnoses within our healthcare system. The proportion of subjects not undergoing further testing to confirm diagnosis was similar among whites $(n=23,21.9 \%)$, blacks $(n=6,17.7 \%)$, and Asians ( $n=9,17.7 \%$ ); no Hispanics lacked objective confirmatory data.

Broad interracial differences were seen among the age at diagnosis $(P<0.001)$, disease duration $(P=0.003)$, family history of $\operatorname{IBD}(P=0.01)$, and smoking $(P<$ 0.001). Analysis comparing individual race pairs revealed that Asians were diagnosed with IBD at older ages (41.0 years) than whites (30.5 years, $P<0.001)$ and blacks (31.7 years, $P=0.005)$. Hispanics were diagnosed at older ages (37.1 years) than whites $(P=0.01)$. Asians and Hispanics had shorter disease durations (5.4 and 5.2 years, respectively) than whites or blacks (8.6 and 12.1 years, respectively; $P \leq 0.05$ for each comparison). A higher proportion of whites $(25.7 \%)$ had a family history of IBD than blacks $(8.8 \%, P=0.04)$ or Asians $(5.9 \%$, $P=0.003)$. Blacks (52.9\%) were more likely to be current smokers than whites $(23.8 \%, P=0.004)$, Hispanics $(5.7 \%$, $P<0.001)$, or Asians (4.8\%, $P<0.001)$ (see Table 2 ). 
Fig. 1 Inflammatory bowel disease (IBD) subtype by race. ${ }^{*} P=0.053$ compared with blacks, ${ }^{* *} P=0.015$ compared with blacks
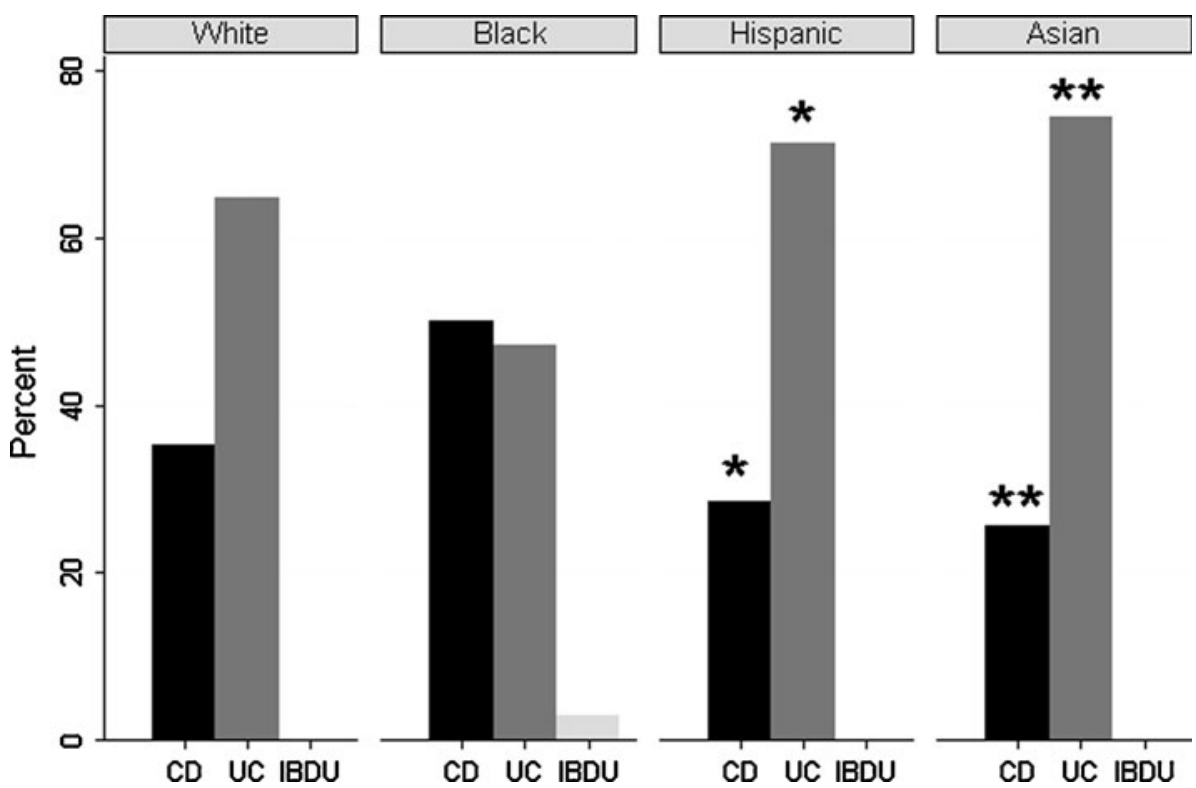

\section{IBD Subtype}

The proportion of blacks with CD ( $n=17,50 \%)$ appeared to be higher than other race groups (whites, $n=37,35.2 \%$; Hispanics, $n=10,28.6 \%$; Asians, $n=13,25.5 \%$ ), despite a $P$-value of 0.11 in the contingency table analysis. Given this observation, we compared the proportions of blacks with $\mathrm{CD}$ to the other three race groups individually. In this analysis, blacks had significantly higher proportions of $\mathrm{CD}$ than Asians $(P=0.015)$. Comparisons with whites $(P=0.095)$ and Hispanics $(P=0.053)$ were not statistically significant (see Fig. 1).

\section{Montreal Classification}

For patients with $\mathrm{CD}$, several interesting findings were observed, including relatively high proportions of L2 disease in Asians ( $n=7,53.9 \%)$ and B1 disease in Hispanics ( $n=8,80 \%$ ), and a lack of L1 disease in Hispanics or Asians. However, the analysis of contingency tables did not reveal statistically significant race-based differences in the Montreal classification of CD.

For patients with UC, the proportions of Hispanic and Asian patients with E3 disease (68.0 and 62.5\%, respectively) appeared to be greater than whites or blacks (56.1 and $50.5 \%$, respectively), but statistically significant interracial differences were not identified $(P=0.14)$ (see Table 3).

\section{Medication Use}

Broad interracial differences were identified among lifetime immunomodulator use $(P=0.021)$. Use was significantly lower among Hispanics $(n=3,8.6 \%)$ compared with whites $(n=26,34.3 \%, P=0.003)$ and blacks $(n=9$, $26.5 \%, \quad P=0.05)$. Contingency table analysis also suggested probable interracial differences in lifetime 5-aminosalicylate $(5$-ASA) use $(P=0.056)$ and lifetime steroid use $(P=0.058)$, so we performed individual interracial comparisons. 5-ASA use was less common among Hispanics $(n=22,77.1 \%)$ and blacks $(n=27$, $79.4 \%)$ compared with whites $(n=97,92.4 \%, P<0.05$ for each comparison). Additionally, steroid use was less common among Hispanics ( $n=12,34.3 \%)$ compared with whites $(n=63,60.0 \%, P=0.008)$ and blacks $(n=20$, $58.8 \%, P=0.041)$. Medication was otherwise similar among races (see Table 4 ).

\section{Surgery}

Although surgery for CD appeared to be more common in blacks, no significant interracial differences were identified $(P=0.35)$. Proportions of UC patients undergoing surgery were similar across races $(P=0.997)$ (see Table 4$)$.

\section{Discussion}

Among IBD patients receiving gastroenterological care in our ethnically diverse healthcare system, we identified several significant interracial differences in historical IBD factors, most notably age at diagnosis, duration of disease, and family history of IBD. Contrary to our hypothesis, IBD subtype and Montreal classification were largely similar among race groups. Furthermore, only minimal differences in the medical and surgical management of IBD were 
Table 3 Montreal classification by race

\begin{tabular}{|c|c|c|c|c|c|c|}
\hline & Total population $^{\mathrm{a}}$ & White & Black & Hispanic & Asian & $P$-value ${ }^{\mathrm{b}}$ \\
\hline \multicolumn{7}{|c|}{ Crohn's disease $(n=77)^{\mathrm{c}}$} \\
\hline \multicolumn{6}{|c|}{ Montreal A class, no. $(\%)$} & 0.12 \\
\hline A1 & $9(11.7)$ & $6(16.2)$ & $3(17.7)$ & $0(0)$ & $0(0)$ & \\
\hline $\mathrm{A} 2$ & $42(54.6)$ & $22(59.5)$ & $10(58.8)$ & $5(50.0)$ & $5(38.5)$ & \\
\hline A3 & $26(33.8)$ & $9(24.3)$ & $4(23.5)$ & $5(50.0)$ & $8(61.5)$ & \\
\hline \multicolumn{6}{|c|}{ Montreal L class, no. (\%) } & 0.30 \\
\hline L1 & $8(10.4)$ & $4(10.8)$ & $4(23.5)$ & $0(0.0)$ & $0(0.0)$ & \\
\hline $\mathrm{L} 2$ & $23(29.9)$ & $9(24.3)$ & $5(29.4)$ & $2(20.0)$ & $7(53.9)$ & \\
\hline L3 & $43(55.8)$ & $22(59.5)$ & $7(41.2)$ & $8(80.0)$ & $6(46.2)$ & \\
\hline L4 modifier & $11(14.9)$ & $4(11.4)$ & $4(25)$ & $0(0.0)$ & $3(23.1)$ & \\
\hline \multicolumn{6}{|c|}{ Montreal B class, no. (\%) } & 0.08 \\
\hline B1 & $53(68.8)$ & $23(62.2)$ & $12(70.6)$ & $8(80.0)$ & $10(76.9)$ & \\
\hline B2 & $11(14.3)$ & $6(16.2)$ & $5(29.4)$ & $0(0.0)$ & $0(0.0)$ & \\
\hline B3 & $13(16.9)$ & $8(21.6)$ & $0(0.0)$ & $2(20.0)$ & $3(23.1)$ & \\
\hline Perianal modifier & $15(19.5)$ & 7 (18.9) & $5(29.4)$ & $2(20.0)$ & $1(7.7)$ & \\
\hline \multicolumn{7}{|c|}{ Ulcerative colitis $(n=137)^{\mathrm{d}}$} \\
\hline \multicolumn{6}{|c|}{ Montreal E class, no. $(\%)$} & 0.14 \\
\hline E1 & $23(16.8)$ & 9 (13.6) & $3(21.4)$ & $4(16.0)$ & 7 (21.9) & \\
\hline $\mathrm{E} 2$ & $33(24.1)$ & $20(30.3)$ & $4(28.6)$ & $4(16.0)$ & $5(15.6)$ & \\
\hline E3 & $81(59.1)$ & $37(56.1)$ & $7(50.0)$ & $17(68.0)$ & $20(62.5)$ & \\
\hline
\end{tabular}

a Includes three patients with "other" race

b $P$-values calculated using contingency tables and Pearson's $\chi^{2}$ or Fisher's exact test, as appropriate

${ }^{c}$ Montreal L and B classes exclude the three patients with undocumented Montreal classification ( $n=74$ for these classes); A class was known for all subjects $(n=77)$

${ }^{\mathrm{d}}$ Excludes 13 patients with undocumented disease extent

Table 4 Medication use and surgical history by race

\begin{tabular}{|c|c|c|c|c|c|c|}
\hline & $\begin{array}{l}\text { Total population } \\
(n=228)^{\mathrm{a}}\end{array}$ & $\begin{array}{l}\text { White } \\
(n=105)\end{array}$ & $\begin{array}{l}\text { Black } \\
(n=34)\end{array}$ & $\begin{array}{l}\text { Hispanic } \\
(n=35)\end{array}$ & $\begin{array}{l}\text { Asian } \\
(n=51)\end{array}$ & $P$-value ${ }^{\mathrm{b}}$ \\
\hline \multicolumn{7}{|l|}{ Lifetime medication use } \\
\hline 5-aminosalicylates, no. (\%) & $196(87.1)$ & $97(92.4)$ & $27(79.4)$ & $27(77.1)$ & $45(88.2)$ & 0.056 \\
\hline Immunomodulators, no. (\%) & $59(26.2)$ & $26(34.3)$ & $9(26.5)$ & $3(8.6)$ & $11(21.6)$ & 0.021 \\
\hline Steroids (oral or intravenous), no. (\%) & $121(53.8)$ & $63(60.0)$ & $20(58.8)$ & $12(34.3)$ & $26(51.0)$ & 0.058 \\
\hline Topical therapy, no. (\%) & $100(44.4)$ & $48(45.7)$ & $14(41.2)$ & $13(37.1)$ & $25(49.0)$ & 0.71 \\
\hline $\begin{array}{l}\text { Tumor necrosis factor inhibitors, } \\
\text { no. }(\%)\end{array}$ & $23(10.2)$ & $12(11.4)$ & $4(11.8)$ & $3(8.6)$ & $4(7.8)$ & 0.88 \\
\hline \multicolumn{7}{|l|}{ Surgical history } \\
\hline $\begin{array}{l}\text { Any surgery for Crohn's disease, } \\
\text { no. }(\%)\end{array}$ & $32(41.6)$ & $15(40.5)$ & $10(58.8)$ & $3(30.0)$ & $4(30.8)$ & 0.35 \\
\hline $\begin{array}{l}\text { Any surgery for ulcerative colitis, } \\
\text { no. }(\%)\end{array}$ & $19(12.7)$ & $8(11.8)$ & $2(12.5)$ & $3(12.0)$ & $5(13.2)$ & 0.997 \\
\hline
\end{tabular}

"Includes three patients with "other" race

b $P$-values calculated using contingency tables and Pearson's $\chi^{2}$ or Fisher's exact test, as appropriate

identified, and prominent differences in disease severity and management comparing whites to minorities were not appreciated.
The combination of older age at diagnosis and shorter disease duration among Asians and Hispanics compared with whites and blacks is a novel finding compared with 
the two existing studies comparing IBD among three or more race groups $[12,13]$. In 2005, Basu et al. reported a cross-sectional analysis of 148 ethnically diverse IBD patients drawn from a single university-based gastroenterology clinic in Houston, TX [12]. Age at diagnosis and disease duration did not vary by race. The sample size was relatively small, limiting interrace comparisons. The recruitment of subjects from a single university-based clinic could confer selection bias. In 2006, Nguyen and colleagues published a cross-sectional analysis of 1,126 ethnically diverse IBD patients drawn from several centers [13]. Age at diagnosis did not vary by race, and disease duration was not reported. Although the study was large, different race groups were recruited almost exclusively from separate sites. This could not be controlled for in the data analysis, and site-specific factors may have confounded the results.

Our findings lend support to the hypothesis that environmental factors contribute to IBD pathogenesis and course, and that changes in environmental exposures may increase IBD risk. Specifically, though we lack data on the immigration status of our subjects, it is likely that proportionately more Hispanic and Asian subjects in our study were first-generation immigrants compared with blacks or whites. Previous studies document increased risk of IBD when persons move from areas of low IBD prevalence to areas of higher prevalence [23]. This phenomenon may affect our patient population, which could explain the later age at diagnosis and shorter disease duration among Hispanics and Asians. Our study population may differ in this regard compared with the subjects in the Basu and Nguyen studies, which may account for our unique findings. This hypothesis is further supported by the lower family history of IBD in Asians compared with whites (and a similar pattern comparing Hispanics with whites, despite the lack of statistical significance, $P=0.078$ ). It is important that physicians caring for recent immigrants from Asian and Latin American nations be aware of this likely increased risk for IBD, particularly when patients present with nonspecific gastrointestinal complaints of unclear etiology, such as chronic diarrhea, recurrent abdominal pain, or rectal bleeding. In such patients, delayed diagnosis resulting in delayed onset of therapy could result in worse outcomes [24].

Contrary to our hypothesis, only modest interracial differences were seen in the IBD subtype. The most notable finding was a higher proportion of CD in blacks compared with Asians and similar-appearing differences compared with Hispanics and whites that were not statistically significant $(P=0.053$ and 0.095 , respectively). Similar differences between blacks and other race groups were not seen in the Basu or Nguyen studies [12, 13]. Interracial differences in environmental exposures and/or genetics may account for these findings. Specifically, high rates of smoking among blacks in our study may contribute to the differences, a hypothesis supported by similar rates of both smoking and CD in blacks compared with whites in the Basu and Nguyen studies [12, 13]. Genetic factors contributing to IBD are not well-characterized among nonwhite patients. Blacks, Hispanics, and Asians with $\mathrm{CD}$ are less likely than whites to have common NOD2 mutations [25-27]. Additionally, multiple studies of IBD genetics have been recently published among Asian cohorts [28-30]. The genetic study of IBD among nonwhite patients remains limited and is an important area for future research.

Also contrary to our hypothesis, we identified no significant interracial differences in the Montreal classification. This may be due, in part, to our study design, in which patients were drawn from the same center, which reduces center-specific influences that may affect interracial comparisons in other studies. For CD patients, the lack of differences may also reflect, in part, limitations of a modest sample size. For example, no Hispanic or Asian patients had isolated terminal ileal $\mathrm{CD}$, and no blacks had penetrating $\mathrm{CD}$, yet the $P$-values did not indicate statistical significance. It is possible that, with a larger sample, significant differences would be seen. For UC patients, however, proportions of patients with proctitis, left-sided colitis, and extensive colitis were numerically similar among races, suggesting a true lack of interracial difference.

Although minority patients with IBD received different medical and surgical therapy than whites in other studies [12, 13, 31], we identified relatively few interracial differences. Notably, Hispanics received 5-ASA compounds, immunomodulators, and steroids less often than whites. The reasons for this are not clear. Hispanics were not more likely to undergo IBD-related surgery, which might be seen if they had disease of similar severity but were undertreated. It is possible that Hispanics in our study had milder disease, a hypothesis that can only be addressed in a prospective study. The relative lack of interracial differences in the management of IBD may reflect the minimization of race-based healthcare disparities in our healthcare system in which all patients had equal access to healthcare.

Our study population is of lower socioeconomic status than the general United States population, which raises the question of whether socioeconomic status was associated with IBD phenotype or therapy in our patients. Comparing patients of lower and higher monthly income in our population, we identified no significant differences in the IBD phenotype or medical or surgical therapy (data not shown). Comparisons with a higher income population would be an interesting direction for future research.

Our study has several specific strengths. The inclusion of IBD patients from an entire healthcare system may 
reduce selection bias and improve generalizability. Although our patient population is of significantly lower socioeconomic status than the general United States population (mean annual income in our population was $\$ 8,256$ ), the relative proportions of different race groups among our IBD patients were similar to the overall San Francisco population (Table 2). Furthermore, the racespecific proportions of CD versus UC in our study population are similar to those from a large study of the Northern California Kaiser Permanente population (a managed care population in geographic proximity to our center with 3.2 million members; 8,787 IBD patients were included in the study) [32]. These similarities to large populations support the generalizability of our results. All of the subjects in our study had equal healthcare access within the system, receiving care from the same gastroenterology faculty. This reduces potential confounding from site-specific factors and, importantly, disparities in healthcare access.

We identified a relatively modest number of patients with IBD over a 13-year period. This may, in part, reflect the racial breakdown of our overall healthcare system, in which whites are underrepresented and blacks and Hispanics are overrepresented, compared with the overall San Francisco population (Table 2). Because we included only IBD patients seen in the gastroenterology clinic, patients with mild IBD manageable by primary care physicians might not have been referred to the gastroenterology clinic and would, therefore, not be included in our study. Given our modest sample size with many potential dependent variables, we designed our statistical analysis to reduce the risk of committing type I error, which is more counterproductive than type II error. This methodology may not identify all differences that are truly present in our study population. Each of our race groups includes, to varying degrees, an ethnically diverse group of subjects. We do not have detailed information on ethnicity (i.e., Chinese versus Japanese versus Indian for Asians, or Mexican versus Salvadoran for Hispanics), but this is not likely to affect our results in a predictable manner. We relied on ICD9 codes to identify patients with IBD, and it is possible that some IBD patients were not identified due to miscoding. As most patients were seen multiple times in the clinic, and ICD9 codes were entered at each visit, we believe that our study captures the vast majority of IBD patients in our healthcare system, and the utility of using administrative data to identify IBD patients is supported by other authors [33]. Finally, reliance on chart review may result in incomplete data for some patients, but race itself is unlikely to affect data completeness, and this limitation is unlikely to bias our findings.

In summary, we present evidence supporting later age at diagnosis, shorter disease duration, and less frequent family history of IBD among Hispanic and Asian IBD patients.
Despite these differences, the IBD subtype, Montreal disease classification, and medical and surgical therapy were largely similar among races.

Acknowledgments We thank Uma Mahadevan, MD and Jennifer Guy, MD, MAS for their assistance in the manuscript review and editing, and Kjeld Molvig for his assistance in obtaining the data.

Grant support This study was supported, in part, by: (1) the William and Mary Ann Rice Memorial Distinguished Professorship (HFY) and (2) a training grant from the National Institute of Diabetes and Digestive and Kidney Diseases (5T32DK007007-35), National Institutes of Health (JLS).

Conflicts of interest No conflicts of interest exist for any author.

\section{Writing assistance None.}

Open Access This article is distributed under the terms of the Creative Commons Attribution Noncommercial License which permits any noncommercial use, distribution, and reproduction in any medium, provided the original author(s) and source are credited.

\section{References}

1. Lok $\mathrm{KH}$, Hung $\mathrm{HG}, \mathrm{Ng} \mathrm{CH}$, et al. Epidemiology and clinical characteristics of ulcerative colitis in Chinese population: experience from a single center in Hong Kong. $J$ Gastroenterol Hepatol. 2008;23:406-410.

2. Leong RW, Lau JY, Sung JJ. The epidemiology and phenotype of Crohn's disease in the Chinese population. Inflamm Bowel Dis. 2004;10:646-651.

3. Yang SK, Yun S, Kim JH, et al. Epidemiology of inflammatory bowel disease in the Songpa-Kangdong district, Seoul, Korea, 1986-2005: a KASID study. Inflamm Bowel Dis. 2008;14: 542-549.

4. Victoria CR, Sassak LY, Nunes HR. Incidence and prevalence rates of inflammatory bowel diseases, in midwestern of São Paulo State, Brazil. Arq Gastroenterol. 2009;46:20-25.

5. Lok $\mathrm{KH}$, Hung $\mathrm{HG}, \mathrm{Ng} \mathrm{CH}$, et al. The epidemiology and clinical characteristics of Crohn's disease in the Hong Kong Chinese population: experiences from a regional hospital. Hong Kong Med J. 2007;13:436-441.

6. Chow DK, Leong RW, Tsoi KK, et al. Long-term follow-up of ulcerative colitis in the Chinese population. Am J Gastroenterol. 2009; 104:647-654.

7. Yoshida Y, Murata Y. Inflammatory bowel disease in Japan: studies of epidemiology and etiopathogenesis. Med Clin North Am. 1990;74:67-90.

8. Loftus EV Jr. Clinical epidemiology of inflammatory bowel disease: incidence, prevalence, and environmental influences. Gastroenterology. 2004;126:1504-1517.

9. Sewell JL, Yee HF Jr, Inadomi JM. Hospitalizations are increasing among minority patients with Crohn's disease and ulcerative colitis. Inflamm Bowel Dis. 2010;16:204-207.

10. Samimi R, Flasar MH, Kavic S, et al. Outcome of medical treatment of stricturing and penetrating Crohn's disease: a retrospective study. Inflamm Bowel Dis. 2010;16:1187-1194.

11. Portela F, Magro F, Lago P, et al. Ulcerative colitis in a Southern European country: a national perspective. Inflamm Bowel Dis. 2010;16:822-829. 
12. Basu D, Lopez I, Kulkarni A, et al. Impact of race and ethnicity on inflammatory bowel disease. Am J Gastroenterol. 2005;100: 2254-2261.

13. Nguyen GC, Torres EA, Regueiro M, et al. Inflammatory bowel disease characteristics among African Americans, Hispanics, and non-Hispanic Whites: characterization of a large North American cohort. Am J Gastroenterol. 2006;101:1012-1023.

14. Bindman AB, Chen A, Fraser JS, et al. Healthcare reform with a safety net: lessons from San Francisco. Am J Manag Care. 2009;15:747-750.

15. University of California San Francisco (UCSF) School of Medicine-San Francisco General Hospital. Facts and figures. Available online at: http://www.medschool.ucsf.edu/sfgh/factsfigures. Accessed March 15, 2010.

16. McWilliams JM, Meara E, Zaslavsky AM, et al. Differences in control of cardiovascular disease and diabetes by race, ethnicity, and education: U.S. trends from 1999 to 2006 and effects of Medicare coverage. Ann Intern Med. 2009;150:505-515.

17. Moylan CA, Brady CW, Johnson JL, et al. Disparities in liver transplantation before and after introduction of the MELD score. JAMA. 2008;300:2371-2378.

18. U.S. Census Bureau. State and county quick facts for San Francisco, CA, 2008. Available online at: http://quickfacts.census. gov/qfd/states/06/06075.html. Accessed March 15, 2010.

19. Sewell JL, Kushel MB, Inadomi JM, et al. Non-English speakers attend gastroenterology clinic appointments at higher rates than English speakers in a vulnerable patient population. J Clin Gastroenterol. 2009;43:652-660.

20. Chen AH, Kushel MB, Grumbach $\mathrm{K}$, et al. Practice profile. A safety-net system gains efficiencies through 'eReferrals' to specialists. Health Aff (Millwood). 2010;29:969-971.

21. Satsangi J, Silverberg MS, Vermeire S, et al. The Montreal classification of inflammatory bowel disease: controversies, consensus, and implications. Gut. 2006;55:749-753.

22. Winker MA. Measuring race and ethnicity: why and how? JAMA. 2004;292:1612-1614.

23. Tsironi E, Feakins RM, Probert CS, et al. Incidence of inflammatory bowel disease is rising and abdominal tuberculosis is falling in Bangladeshis in East London, United Kingdom. Am J Gastroenterol. 2004;99:1749-1755.

24. Cosnes J. Can we modulate the clinical course of inflammatory bowel diseases by our current treatment strategies? Dig Dis. 2009;27:516-521.

25. Dassopoulos T, Nguyen GC, Talor MV, et al. NOD2 mutations and anti-Saccharomyces cerevisiae antibodies are risk factors for Crohn's disease in African Americans. Am J Gastroenterol. 2010;105:378-386.

26. Kugathasan S, Loizides A, Babusukumar U, et al. Comparative phenotypic and CARD15 mutational analysis among African American, Hispanic, and White children with Crohn's disease. Inflamm Bowel Dis. 2005;11:631-638.

27. Inoue N, Tamura K, Kinouchi Y, et al. Lack of common NOD2 variants in Japanese patients with Crohn's disease. Gastroenterology. 2002;123:86-91.

28. Yamazaki K, Takahashi A, Takazoe M, et al. Positive association of genetic variants in the upstream region of NKX2-3 with Crohn's disease in Japanese patients. Gut. 2009;58:228-232.

29. Tanaka M, Arimura Y, Goto A, et al. Genetic variants in surfactant, pulmonary-associated protein D (SFTPD) and Japanese susceptibility to ulcerative colitis. Inflamm Bowel Dis. 2009;15: 918-925.

30. Zhang HF, Qiu LX, Chen Y, et al. ATG16L1 T300A polymorphism and Crohn's disease susceptibility: evidence from 13,022 cases and 17,532 controls. Hum Genet. 2009;125:627-631.

31. Flasar MH, Johnson T, Roghmann MC, et al. Disparities in the use of immunomodulators and biologics for the treatment of inflammatory bowel disease: a retrospective cohort study. Inflamm Bowel Dis. 2008;14:13-19.

32. Herrinton LJ, Liu L, Fireman B, et al. Time trends in therapies and outcomes for adult inflammatory bowel disease, Northern California, 1998-2005. Gastroenterology. 2009;137:502-511.

33. Farrokhyar F, McHugh K, Irvine EJ. Self-reported awareness and use of the International Classification of Diseases coding of inflammatory bowel disease services by Ontario physicians. Can J Gastroenterol. 2002;16:519-526. 